\title{
Increasing soil pH enhances the network interactions among bacterial and archaeal microbiota in alpine grasslands of the Tibetan Plateau
}

\section{Beibei Chen}

Lanzhou University

Shuaiwei Luo

Lanzhou University

Beibei Ma

Lanzhou University

Wei Qi

Lanzhou University

Changdong Cao

Lanzhou University

Zhigang Zhao

Lanzhou University

Shuo Jiao

Northwest Agriculture and Forestry University

Guozhen Du

Lanzhou University

Xiaojun Ma ( $\nabla$ xjma@lzu.edu.cn )

Lanzhou University https://orcid.org/0000-0002-4070-7858

\section{Research}

Keywords: Soil pH, Soil microbiota, Co-occurrence network, Ecological cluster, Tibetan Plateau

Posted Date: December 17th, 2019

DOI: https://doi.org/10.21203/rs.2.18880/v2

License: () (1) This work is licensed under a Creative Commons Attribution 4.0 International License.

Read Full License 
The authors have withdrawn this preprint from Research Square 